\title{
The Technique of Security Print on Textiles with a Hidden Sign in the Near-Infrared Spectrum
}

\author{
Jana ŽILJAK GRŠIĆ*, Denis JUREČIĆ, Branka MORIĆ KOLARIĆ, Tonči JELIČIĆ
}

\begin{abstract}
The INFRAREDESIGN $囚$ is introduced into the fabric dyeing technology in order to give a new dimension to security cameras in urban areas. The visible pattern of colors also contains a carefully designed hidden image. The hidden image is detected instrumentally in the infrared area. The arrangement of pigments on the fabric is determined using computer graphics by programming dual, "twin" colorants. Recipes for ink components consisting of colorants cyan, magenta, yellow and black are proposed in this article. The inks differ in monochromatic photography in the near-infrared spectrum. The clothes have two images, two independent pieces of information One is intended for the visible spectrum and can be seen with the naked eye in daylight. The other image is separated (detected) with a camera which "sees" the intended infrared graphics. Cameras in the streets of our cities observe the environment during the day and night. Through the lens of the "night camera", the interested observer discovers messages designed on his or her favorite brand. The clothes are given new value in the eyes of the observer; the brand is elevated to a new level of "dual communication". Security print is a combination of vector and pixel graphics which manifests itself in the visible and near-infrared spectrum.
\end{abstract}

Keywords: hidden image; infrared brand; near Infrared design; night imaging; security print

\section{INTRODUCTION}

Cameras for daytime and nighttime recording are installed in city streets, in private and business spaces. We have taken advantage of the properties of security cameras and observe the environment day and night. One image is in the visible (V) spectrum from 400 to $750 \mathrm{~nm}$, while the $\mathrm{Z}$ image is in the near-infrared $(Z)$ spectrum from $1000 \mathrm{~nm}$. The ability to record during the day and night initiated the development of a new type of fashion design for these two spectra [1]. A hidden image, which manifests itself at night observed through security cameras is added to clothes, e.g. uniforms of all kinds [2]. Security cameras in urban areas are adjusted using blockades for daylight [3]. There is a wide range of cameras which recognize only NIR-Z radiation. Small cameras for the detection of the $Z$ sign are used in banks to verify the authenticity of bills. Cameras used in forensics can have up to twenty barrier filters in the range from 400 to $1000 \mathrm{~nm}$ [4]. Although many security cameras use the daytime solar component of the NIR spectrum, this article uses the term "Night Camera" just for the sake of tradition. The introduction of this duality for security cameras enables us to observe NIR radiation in daylight as well as hidden $\mathrm{Z}$ image [5]. Clothes today are rich in colors when viewed with the naked eye in daylight. We recognize people, vehicles, nature, objects due to their different coloration. Night recording with NIR-Z cameras is monochrome, gray, and most colors do not absorb NIR radiation [6]. Most NIR photographs are white [7]. Conventional night cameras can capture objects and clothes only to a very small extent. Therefore, the dyeing of fabrics in accordance with the properties of twin colorants in the NIR spectrum is proposed [8].

The same color can be produced in many ways by mixing different components. Twins of the same color are based on the idea that they have different material components with regard to the absorption and detection of near-infrared light.

INFRAREDESIGN is based on the idea of combining two pixel images, one of which is intended for the visible spectrum (V), while the other manifests itself in the NIR spectrum (Z) [9]. In published work with the IRD security technique for printing documents, solutions have been proposed for the separation of colorants using a special GCR method called VZ separation [10]. Colorants intended for the NIR-Z spectrum are also called "night colors".

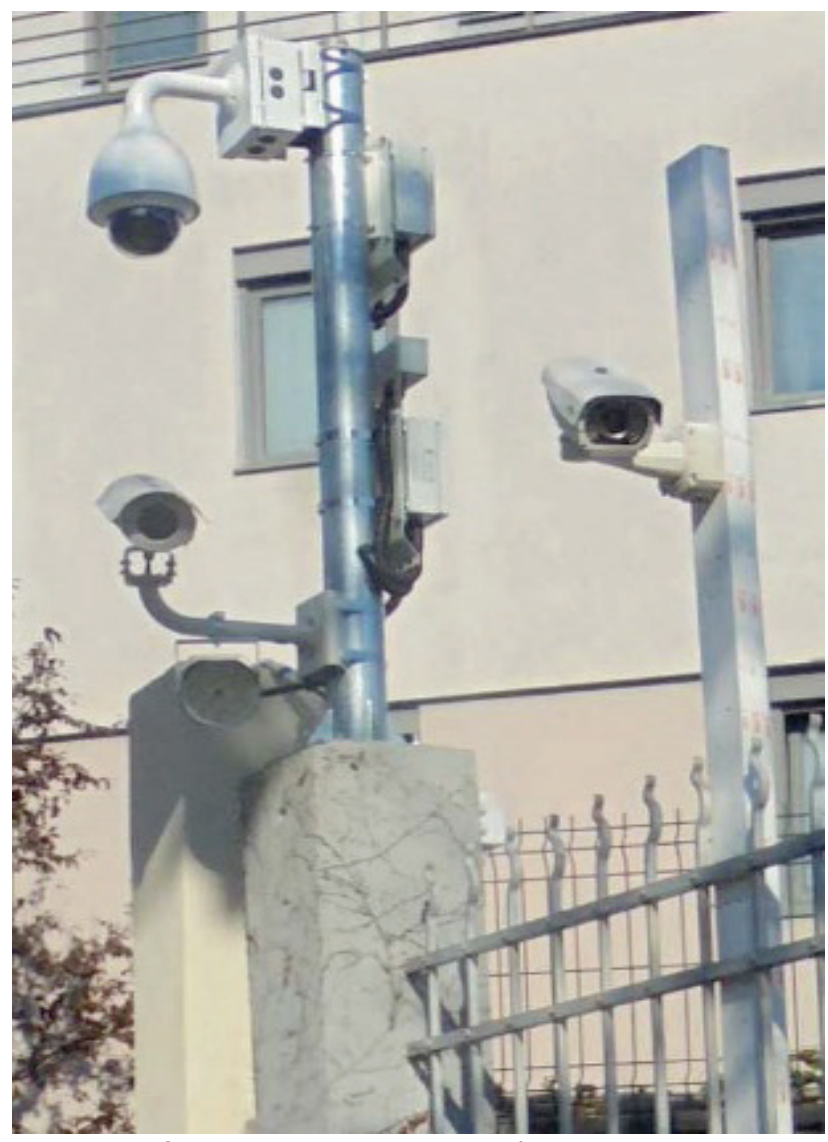

Figure 1 Security cameras in an urban area for daytime and nighttime surveillance

In this article we introduce something new in INFRAREDESIGN ${ }^{\circledR}$ - the design of the first image in linear vector graphics, which are typical of security print for documents and securities. The precision and definition of the thin lines prevents the scanning and photographing 
of vector graphics. The innovation in this article is the method of separating ink for prepress in order to print two different graphics. The design of the vector definition of lines for the visible spectrum is followed. Vector graphics will be translated into pixel graphics (4-bit), but in very high resolution.

\section{TWINS OF COLORS AND COLORANTS FOR SCREEN PRINTING OF FABRICS}

The authenticity of products is determined through a dual definition of graphics. Colors are defined as twins, which ensure duality in the visible and near-infrared spectrum. Colorants are separated with VZ separation for print with CMYK colorants. The planned duality of the image with twin colors is built into the product, which has its own infrared protection.

The range of colors visible to the naked eye is limited to wavelengths between 400 and $700 \mathrm{~nm}$. Colors which extend beyond the visible spectrum into the wavelengths of the near-infrared spectrum from $1000 \mathrm{~nm}$ have a response in both spectra. Pairs of colors - twin colors - are prepared using computer graphics so that they have the same $L \times a \times b$ values, but different CMYK values. Twin inks are of identical color tone in print, but have a completely different absorption of NIR light. There are four colors in Fig. 3. Each color is realized in three different blends, three different compositions. The four chosen colors from vector graphics in the visible spectrum are shown as twins for the coverage of carbon black color of 40,30 and zero percent. The goal is to get as many color pairs (twin inks) as possible which will look identical in print and whose difference in color $\Delta \mathrm{E}$ will be less than two $(\Delta E<2)[11]$.

New twin colors are achieved in a few steps. The first step of recipe dyes is calculated with the mathematical relations published in Technical Gazette [12]. The second step is to print the twins, measure the $\Delta E$ and perform spectrography to correct the quantities of process dyes, because the print is made by digital printing on canvas.

In the design with hidden images, strict relations are set for the GCR method of replacement of C, M, Y with carbon black ink.
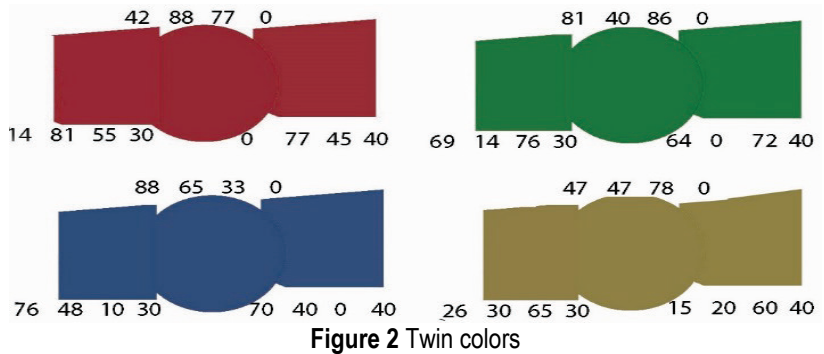

For every color tone used in this experiment, recipes for pairs of twin colors are first determined. The value of color K (carbon black) which carries the infrared effect has a maximum value of 40 percent coverage. The intended design with twin colors ensures the duality of image in print. The space for information is expanded into the NIR spectrum. Night recording reveals information which acquire a new meaning.

Table 1 Recipes of twin colorants in raster printing on white fabric

\begin{tabular}{|c|c|c|c|c|c|}
\hline \multirow{2}{*}{ ink } & Line graphics & \multicolumn{4}{|c|}{ twin colors, screen printing on fabric } \\
\cline { 2 - 5 } & setrgbcolor & $\mathrm{C}, \mathrm{M}, \mathrm{Y}, \mathrm{K}=0$ & $\mathrm{C}, \mathrm{M}, \mathrm{Y}, \mathrm{K}=30$ & $\mathrm{C}, \mathrm{M}, \mathrm{Y}, \mathrm{K}=40$ \\
\hline red & 0.580 .120 .23 & $42,88,77$ & $14,81,55$ & $0,77,45$ & $36 \times a \times b$ \\
\hline blue & 0.120 .350 .67 & $88,65,33$ & $76,48,10$ & $70,40,0$ & $32 \times 0 \times-30$ \\
\hline green & 0.190 .600 .14 & $81,40,86$ & $69,14,76$ & $64,0,72$ & $44 \times-37 \times 23$ \\
\hline brown & 0.530 .530 .22 & $47,47,78$ & $26,30,65$ & $15,20,60$ \\
\hline
\end{tabular}

Once the palette of pairs of twin colors is determined, taking into account the technique of screen printing, the inks for textiles and the material onto which color will be applied, the design and production of the product begin. The designer chooses and creates the image which will be seen with the naked eye and the image which will be hidden. Two images are combined into one through VZ separation of colorants. The prints thus produced, when seen with the naked eye, do not reveal that they contain "infrared information". Only night recording reveals the other, hidden image.

The designer designs and processes images in one of the standard graphic programs. When he determines the image which will be visible and the image which will be hidden, he begins the conversion using the VZ separation of CMYK channels. The first RGB graphic is prepared for the visible part of the spectrum, while the other will be used for the hidden infrared image. The first phase is the conversion of the visible image from the RGB state into the CMY state, where a special GCR method is conducted under the conditions of $\mathrm{VZ}$ separation, which removes the black component in channel $\mathrm{K}$. The pigments which make up the colorants cyan, magenta and yellow, when observed in infrared light, have no response in the infrared area from
$1000 \mathrm{~nm}$ [1]. The image with the infrared information is placed in channel K. Special VZ separation differs from conventional CMYK separation because VZ separation keeps the second image in the infrared area in channel $\mathrm{K}$ while simultaneously keeping the visible image unchanged.

\section{TECHNIQUE OF PRINT ON TEXTILE WITH INVISIBLE GRAPHICS}

The textile contains two independent graphics printed using twin colors. Algorithms for combining two independent digital records, RGB and Gray, into one prepress for $\mathrm{VZ}$ separation of colors have been developed. The recipes for the parameters of color separation are designed for the technique of print on textile with inks for screen printing. Our eyes see twin colors as the same color tone in daylight; however, they are completely different in the near-infrared spectrum. The range of wavelengths used in planned textile printing is from 400 to $1000 \mathrm{~nm}$.

An application was created for VZ separation which uses the determined twin colors to combine the two graphics into one image visible to the naked eye and one that can be viewed only instrumentally. Our infrared 
graphics belong to the field of security print. It is necessary to use thin lines and alternately bold surfaces with Bezier algorithm. The visual image (named "V" for "visual") is a computer graphic designed as a line vector graphic together with the surfaces within lines (Fig. 3). The image in vector format opens in .AI format [13]. The new solution of combining two images is programmed in PostScript language where the colors for line graphics are defined as RGB colors. PostScript was chosen because it allows the programming of both vector and pixel graphics in the same digital record at the same time. Their combining in the final prepress is planned for printing with inks in the screen printing technique.

The hidden image is a portrait (of the first author of the article). The image is multi-tone, monochromatic (gray), designed as a pixel graphic with only four bits for every colour in the image. The aim is for this image to appear only when viewed through the $\mathrm{Z}$ camera with filters adjusted to recognize light from $1000 \mathrm{~nm}$ [2]. Camera Z does not let through the visible spectrum of light. The new model of prepress for V - NIR print, where pixel graphics $\mathrm{V}$ and line vector graphics for the near-infrared spectrum are combined. VZ separation is the merging of images $\mathrm{V}$ and $\mathrm{Z}$ in pixel graphics. The image for printing is prepared for the standard printing color scale $\mathrm{C}, \mathrm{M}, \mathrm{Y}, \mathrm{K}$ in the resolution of 600 tpi, which will ensure that the lines are continuous after printing.

Most of the surface of line graphics (visual image V) is colorless. The hidden image cannot be achieved in "empty spaces", especially between lines where there were no positive R, G, B values (Fig. 3.).

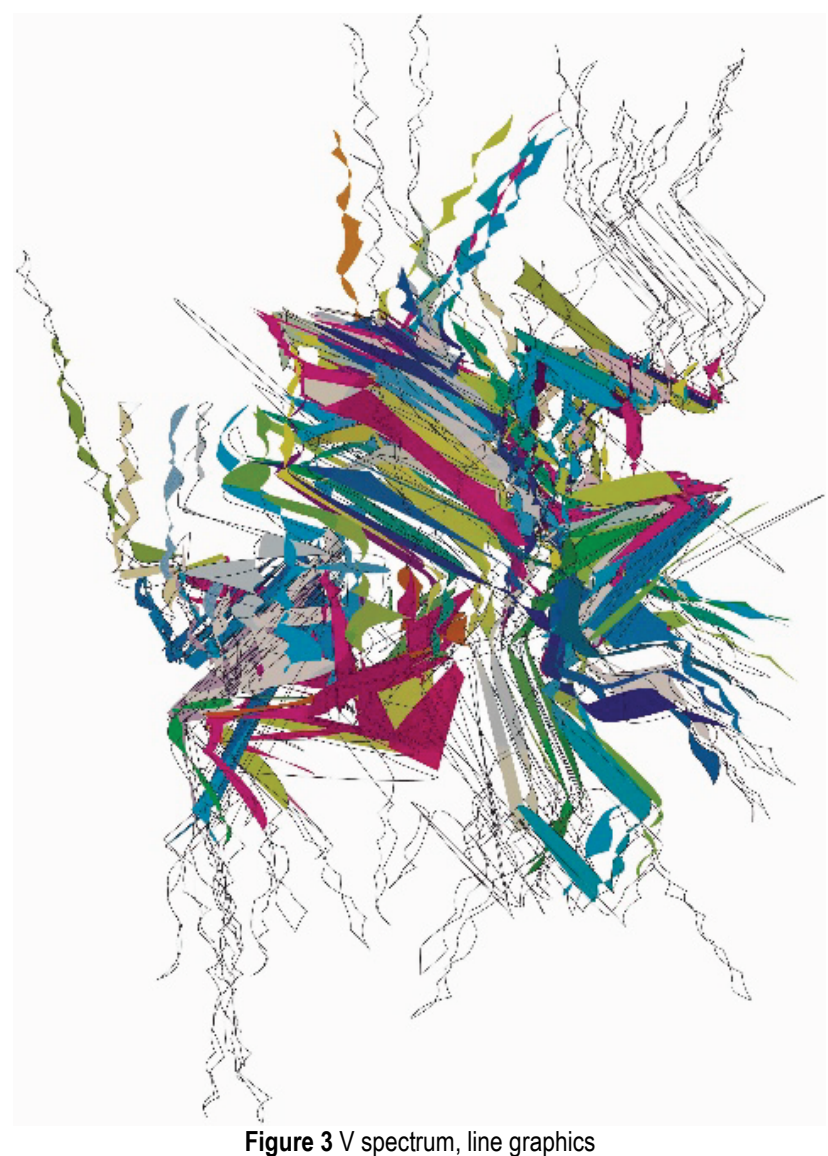

These surfaces are not covered with inks which would result in the replacement of $\mathrm{C}, \mathrm{M}$, Y with carbon black $\mathrm{K}$ from the $\mathrm{Z}$ image. In these places a part of the portrait from the planned hidden image $Z$ is missing. Fig. 4 shows the portrait in two states - two VZ separations were performed with different positions of the portrait $\mathrm{Z}$ in the same visual image $\mathrm{V}$.
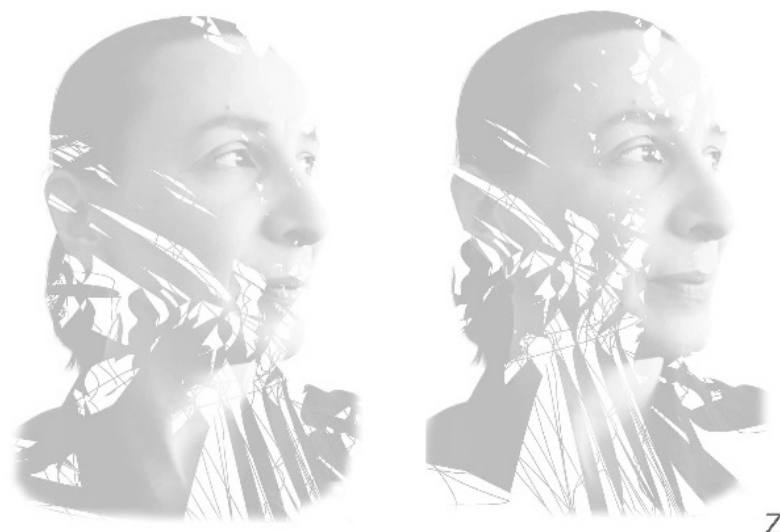

Figure 4 NIR spectrum, pixel graphics

Each product is printed with a digital inkjet plotter that provides an individual, unique solution. The hidden portrait is nested in visible computer graphics (Fig. 6.).The positioning of the hidden image in vector graphics opens up new design possibilities in security print with individualized graphic solutions. The third option of positioning the $Z$ image is added [14]. In Fig. 5 the animation is stopped at $650 \mathrm{~nm}$. The only color from line graphics that remains is cyan. At the end of the animation $(1000 \mathrm{~nm})$ is shown the portrait, in which different areas are not covered than in the portrait in Fig. 3. The combination of line graphics and pixel graphics is a new kind of security. The positioning of one in relation to the other is the key for the protection against scanning and ascertaining the authenticity of the IRD solution.

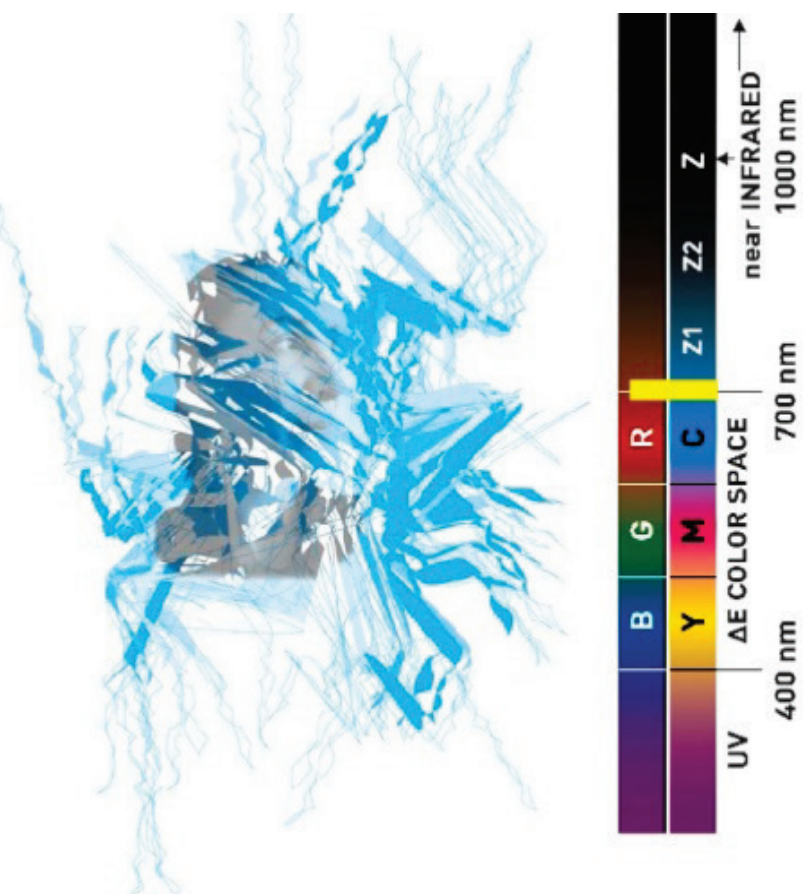

Figure 5 Animation (stopped at $650 \mathrm{~nm}$ ) [14] 


\section{BRAND WITH THE INFRARED SECURITY TECHNIQUE OF PRINT ON FABRIC}

The application of CMYKIR / VZ separation of inks for screen printing on textiles ensures the protection of the brand and confirms the authenticity of the product. Two dresses with a portrait are presented. The photographs were created with ZRGB cameras in an urban area and in nature with flowers.

The images shown carry two pieces of information. The first image is the one we see with the naked eye, photographed in daylight, the way all commercial cameras work. The second image is photographed with a camera adjusted for night recording in the infrared spectrum (1000 $\mathrm{nm})[2]$.

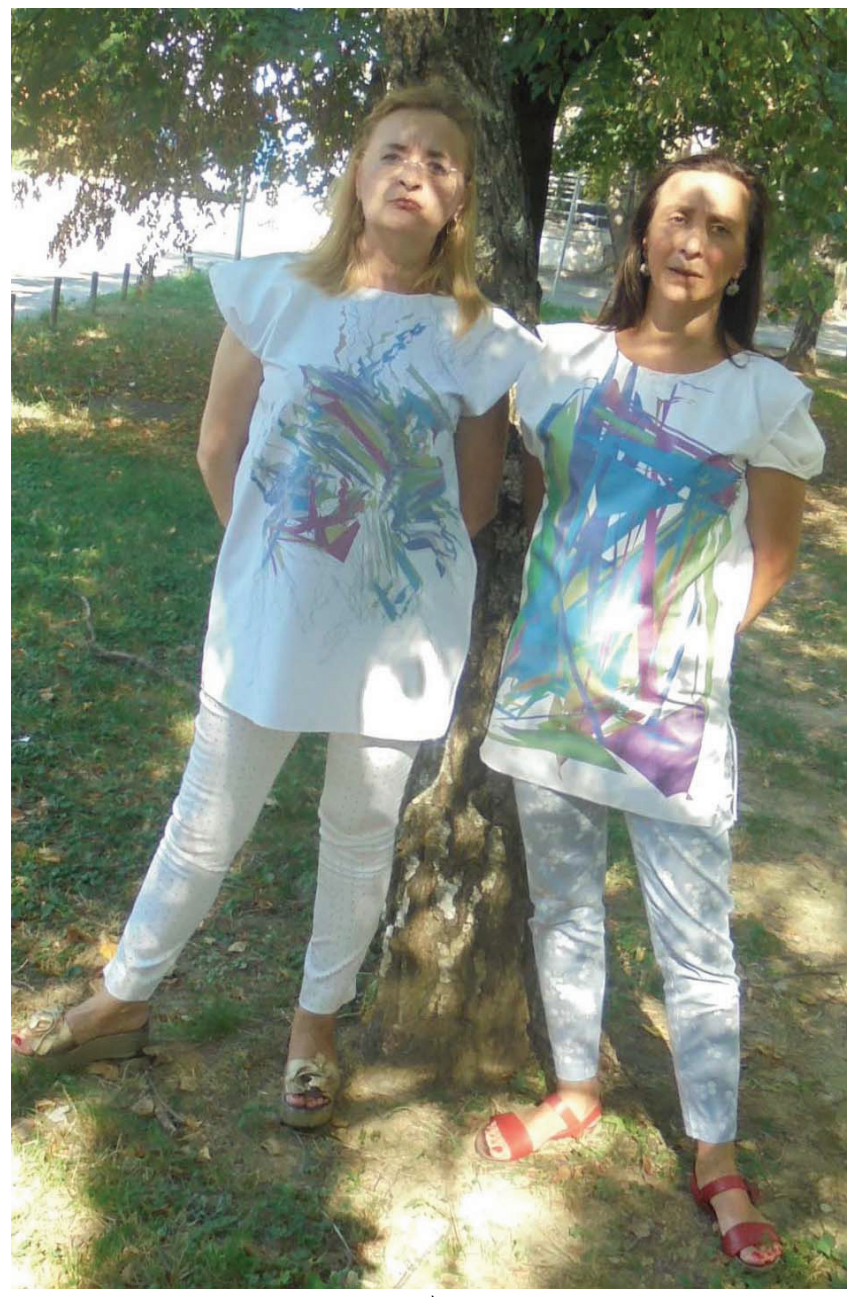

a)

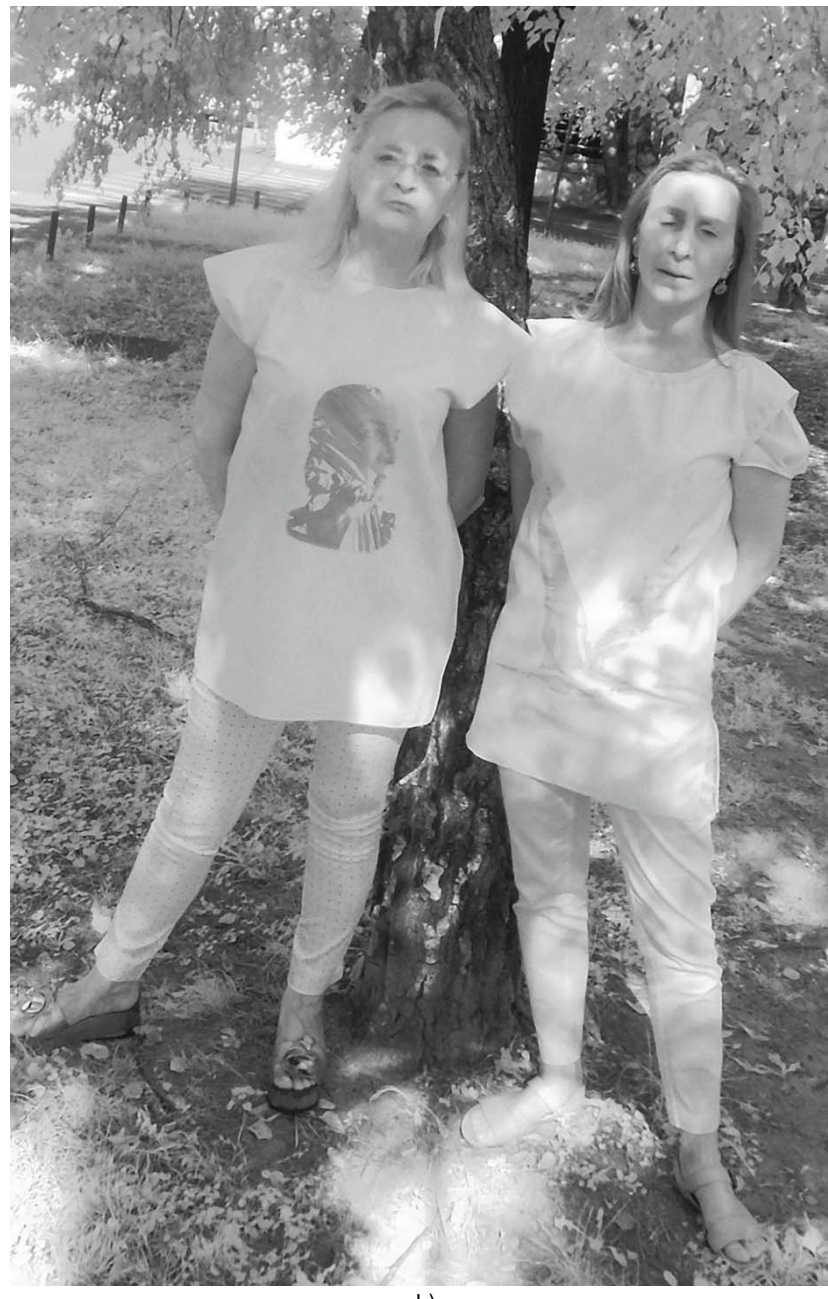

b)
A double graphic is created which combines two images into one. The hidden information is connected with the visible content. Infrared design enables a new kind of communication and offers a range of possibilities of use in the protection of authenticity. The conceptual design of the dual image is left to the designer.

\section{DISCUSSION ON SECURITY ELEMENTS}

The planning of security design begins with programming graphics in vector space which will be visible to the naked eye. Line graphics is key for the quality of the IRD security of printed products. The second image, called the $\mathrm{Z}$ image (portrait), enters the separation as a pixel record. When combined with line graphics, parts of the $\mathrm{Z}$ image disappear in those places where computer line graphics are not covered with printing colors. The planning of the positioning of the hidden image in relation to the lines in the visual computer graphics is the basis for determining the authenticity of the printed IRD graphics on textiles.

Security graphics in IRD procedures includes line graphics as the best solution against scanning or photographing with IR filters. IR photography does not provide the complete input image for the process of $\mathrm{VZ}$ separation, and it does not give the position within the two images.

We introduce twin colors with dual properties into the area of infrared security graphics on clothing. The first twin is made of colorant components which are not recognized by the $\mathrm{Z}$ camera. This twin does not absorb $\mathrm{Z}$ light. The other twins of the same color contain some carbon black ink. How much? This is determined in Fig. 2, which will manifest itself in the NIR spectrum. The success of hiding the $\mathrm{Z}$ sign depends on minimal differences within the set of twin colors, and the value $\Delta \mathrm{E}$ is measured for the visible spectrum. This article gives the recipes for colorants for 
dually connected $\mathrm{V}$ and $\mathrm{Z}$ images which are realized in the screen printing technique on textiles.

\section{CONCLUSION}

The hidden image is detected instrumentally in the infrared area. The visible and the hidden image on textile are realized through computer graphics as NEAR INFRAREDESIGN ${ }^{\circledR}$. The invisible infrared image serves as the protection of the brand. The hidden symbol makes the brand unique and recognizable for the consumer. In order to enrich the content of the brand, a new experience is provided for the consumer - the discovery of messages through a security camera. The visual message is computer graphics programmed as a vector definition of thin lines which resist copying. In the moment when the hidden sign is revealed, the brand acquires new value in the eyes of the observer. This unique design identifies the product and elevates the brand to an entirely new level of communication.

The goal of this research was to determine the practice of marking textile products with individualized graphic elements with infrared effect. Along with the protection of products, this expansion of the visible spectrum into the NIR spectrum also offers the possibility of expanding fashion design into a new spectral area detectable by cameras for night recording. Cities today all have a large number of cameras for daytime and nighttime recording. The IRD fashion design reveals the messages of the brand through the lens of the night vision camera. In the moment of revealing the new information on the clothes, the brand acquires a new value in the eyes of the observer. Dual design identifies the product and elevates the brand to an entirely new level of communication. Designers will have the task of creating dual images and introducing a completely hidden and completely present near-infrared space through this new dimension in textile design. The daytime image belongs to the visible (V) range from 400 to $750 \mathrm{~nm}$, while the nighttime image is in the near-infrared (Z) range from $1000 \mathrm{~nm}$. In this moment of discovery, the brand acquires a new value in the eyes of the observer.

\section{REFERENCES}

[1] Rajković, I. \& Žiljak, V. (2018). Parallel Motion Images in Visual and Near Infrared Spectrum. Tehnički vjesnik, 25(4), 1004-1008. https://doi.org/10.17559/TV-20160610125726

[2] Žiljak, V., Pap, K., \& Žiljak, S. I. (2011). Development of a Prototype for ZRGB INFRAREDESIGN Device. Tehnički vjesnik, 18(2), 153-159. https://hrcak.srce.hr/69578

[3] Rajković, I. \& Žiljak, V. (2016). Usage of ZRGB video camera as a detection and protection system and development of invisible infrared design. Polytechnic \& Design, Zagreb University of Applied Sciences, 4(1), 54-59. https://doi.org/10.19279/TVZ.PD.2016-4-1-07

[4] Projectina Docucenter 4500, SP-2000 color spectroscopy module \& PAG B50 custom designed with 24 barrier filters Projectina AG, Dammstrasse 2, P.O Box CH-9435 Heerbrugg, Switzerland. Retrieved from https://www.ultraforensictechnology.com/en/our-products/

[5] Žiljak, G. J., Golubić, L. T., Žiljak, V., Jurečić, D., \& Rajković, I. (2019). Design on Clothes with Security Printing, with Hidden Information, Performed by Digital Printing. Applied Physics, System Science and Computers
III. APSAC 2018. Lecture Notes in Electrical Engineering, 574, 48-55. https://doi.org/10.1007/978-3-030-21507-1_8

[6] Pogarčić, I., Agić, A., \& Matas, M. (2016). Evaluation of the colorant twins for the neutral grey spectra in infrared graphic procedure. Tehnički vjesnik, 23(6), 1659-1664. https://doi.org/10.17559/TV-20150303132036

[7] Žiljak, J., Tepeš, G. L., Jurečić, D., \& Žiljak, V. (2017). Hidden infrared graphics on a painted canvas. International Journal of Applied Physics, 2, 18-23. https://doi.org/10.1088/1475-7516/2017/09/015

[8] Matas, M., Žiljak, V. J., \& Hoić, A. (2016). Hidden InformationonTextile Designfor theVisual AND Infrared Spectrum. Polytechnic \& Design, 4(3).

[9] Pap, K., Žiljak, I., \& Žiljak, V. J. (2010). Image Reproduction for Near Infrared Spectrum and the Infraredesign Theory. Journal of Imaging Science and Technology, 54(1), 10502-1-10502-9. https://doi.org/10.2352/J.ImagingSci.Technol.2010.54.1.010502

[10] Žiljak, V., Pap, K., Žiljak, S. I., \& Žiljak, V. J. (2012). Managing dual color properties with the Z-parameter in the visual and NIR spectrum. Infrared physics \& technology, 55(4), 326-336. https://doi.org/10.1016/j.infrared.2012.02.009

[11] Glogar, M. I. \& Parac, O. Đ. (2015). Achromatic Hues Matching in Graphic Printing. Actagraphica, 26(1-2), 36-45. Retrieved from https://hrcak.srce.hr/145334

[12] Žiljak, J., Jurečić, D., \& Žiljak, V. (2018). Packaging Design with Hidden Near Infrared Colour Separation, Tehnički vjesnik, 25(3), 211-215. https://doi.org/10.17559/TV-20170705114921

[13] Žiljak, V. http://www.vilko.ziljak.hr/racgraf011.ai

[14] Žiljak, V. http://www.vilko.ziljak.hr/racgraf011.mp4

\section{Contact information:}

\section{Jana ŽILJAK GRŠIĆ}

(Corresponding author)

Zagreb University of Applied Sciences,

Vrbik 8, Zagreb, Croatia

E-Mail: jana@ziljak.hr

Denis JUREČIĆ,

Faculty of Graphic Arts, University of Zagreb

Getaldićeva 2, Zagreb, Croatia

E-Mail: denis.jurecic@grf.hr

Branka MORIĆ KOLARIĆ,

Narodne novine, Zagreb,

Savskigaj, XIII. put 6, Zagreb, Croatia

E-mail: brankamorick@gmail.com

Tonči JELIČIĆ,

Hydrographic Institute of the Republic of Croatia, Split,

Zrinsko-Frankopanska 161, Split, Croatia

E-mail: tonci.jelicic@hhi.hr 